\title{
COMPETÊNCIA EM INFORMAÇÃO: das origens às tendências
}

\author{
INFORMATION LITERACY: \\ from origins to trends
}

Regina Célia Baptista Belluzzo

\begin{abstract}
RESUMO
Apresenta-se a competência em informação, tema considerado de importância para a sociedade contemporânea, desde alguns aspectos histórico-conceituais que envolvem sua origem e as principais mudanças porque tem passado ao longo de sua história. Destacam-se os diferentes fatores que contribuíram para a sua consolidação, salientando-se o seu protagonismo em nível internacional e a sua situação emergente no Brasil. Desse modo, o propósito deste artigo é contribuir com uma descrição teórica a partir de revisão bibliográfica seletiva sobre o tema, oferecendo um panorama desde suas origens até as principais tendências que poderão contribuir para a sociedade brasileira, enquanto um movimento de cidadania e aprendizado ao longo da vida que tem importância vital para que todos tenham acesso e façam uso inteligente da informação e construam conhecimento aplicável às questões de sustentabilidade, desenvolvimento social e inovação no cenário de mudanças em curso.
\end{abstract}

Palavras-chave: Competência em informação. Habilidades em informação.Competência midiática. Era digital.

\section{ABSTRACT}

Information literacy is presented, a theme considered important for contemporary society, from some historical and conceptual aspects that involve its origin and the main changes that it has undergone throughout its history. We highlight the different factors that contributed to its consolidation, highlighting its role at the international level and its emerging situation in Brazil. The purpose of this article is to contribute with a theoretical description from a selective bibliographic review on the theme, offering an overview from its origins to the main trends that may contribute to Brazilian society, as a movement of citizenship and lifelong learning that it is vitally important for everyone to have access to and make intelligent use of information and to build knowledge applicable to issues of sustainability, social development and innovation in the context of ongoing changes.

Keywords: Information literacy. Information skills. Media literacy. Digital era.

Artigo submetido em 06/11/2020 e aceito para publicação em 20/11/2020

1 Docente permanente no Programa de Pós-Graduação em Ciência da Informação.Universidade Estadual Paulista Julio de Mesquita Filho, Brasil. ORCID https://orcid.org/0000-0001-9514-2930.E-mail: rbelluzzo@gmail.com 


\section{INTRODUÇÃO}

Considera-se que a informação é essencial para o sucesso na escola, no trabalho e na vida cotidiana. As pessoas precisam de acesso a informações precisas e confiáveis para tomar decisões acertadas e solucionar problemas. Os cidadãos em uma democracia precisam de informações para decidir como votar nas eleições e nas iniciativas eleitorais. As pessoas também usam as informações na forma de livros, filmes e música para entretenimento e crescimento pessoal. As bibliotecas, museus e arquivos podem fornecer às pessoas acesso a informações vitais por meio de coleções cuidadosamente selecionadas e organizadas, mas o acesso é apenas o primeiro passo. As pessoas também precisam de conhecimentos e habilidades para adotar atitudes para encontrar, avaliar e usar essas informações, um conjunto de capacidades comumente referido como competência em informação.

Inicialmente, fazendo menção a uma rápida linha do tempo, procura-se lembrar que a noção de Competência em Informação (Colnfo) tem como referência a information literacy e o bibliotecário americano Paul Zurkowski, em 1974, sendo considerada uma área de atenção primária no contexto internacional, principalmente, no cenário social atual que se configura como uma sociedade apoiada em informação, conhecimento e tecnologias. Desse modo, no documento intitulado 'The information SERVICE ENVIRONMENT: relationships and priorities', esse autor designa a Competência em Informação como o conjunto de técnicas e habilidades para utilizar a vasta gama de recursos de informação na solução de problemas informacionais e, nessa perspectiva, envolve o reconhecimento do valor da informação e a habilidade de ajustar a informação para atender a distintas necessidades de informação no contexto de explosão informacional (ZURKOWSKI, 1974).

A American Library Association (2008) definiu a competência em informação (Colnfo) como um conjunto de habilidades que exigem que as pessoas reconheçam quando as informações são necessárias e tenham a capacidade de localizar, avaliar e usar efetivamente as informações necessárias. Em outros momentos, existe a descrição da Colnfo como uma prática socialmente situada, sendo necessária para que as pessoas se tornem social e civicamente envolvidas em suas comunidades. Além disso, é um elemento crucial para o sucesso no mundo do trabalho, onde as pessoas estão vivenciando também rápidas mudanças tecnológicas.

A Colnfo passou por mudanças ao longo de sua história a fim de acomodar as novas realidades nas quais tem sido conceituada, pesquisada ou colocada em prática. Diferentes fatores contribuíram para a consolidação dessa competência e podem ser analisados nos níveis teórico e prático. Este 
último, envolvendo a evolução da instrução bibliográfica e conceituações tradicionais de educação do usuário. Nesse sentido, destaca-se que a educação tem sido parte integrante dos serviços das bibliotecas por mais de um século. Assim, as primeiras bibliotecas públicas se concentravam na coleta e organização de materiais, porém, com a disseminação da educação de forma universal, os índices de alfabetização foram ampliados e o interesse do público em geral por livros ejornais cresceu. Como os sistemas e recursos da biblioteca eram uma novidade, os bibliotecários descobriram que precisavam despender tempo ajudando os usuários a adentrar pela biblioteca e conhecer seus recursos. A isso se denominou "instruction or orientation forlibraries" ou educação de usuários (TYCKOSON, 2020). O segundo nível - o teórico, refere-se às perspectivas e estruturas de mudança em educação e ciência da informação. Sob esse olhar, nos dois níveis, é possível argumentar que as mudanças nos ambientes e ecologias dainformação estão no cerne das transformações em ambos e que figuram com destaque no reexame de temas e questões priorizados na sociedade atual, uma vez que os usuários também estão se dedicando para áreas que exigem pensamento mais crítico, tais como: avaliar informações, desenvolver um tópico de pesquisa e questões pesquisáveis, reconhecer notícias falsas, bem como habilidades profissionais e para a vida, como encontrar e se candidatar a empregos online, pesquisar empresas e produtos antes de fazer compras importantes e encontrar informações confiáveis sobre saúde e finanças, porexemplo.

Temos, assim, um novo contexto e novos comportamentos e, vale lembrar que o foco da educação nas bibliotecas tem mudado um pouco com o tempo, em grande parte em resposta às mudanças na tecnologia e à relativa facilidade de acesso à informação, surgindo então uma nova área de atenção - a information literacy ou competência em informação. Entretanto, convém salientar também que a educação de usuários tem por princípio ativo a orientação quanto ao uso da biblioteca, 0 desenvolvimento das habilidades de busca e uso da informação e o incentivo em frequentar bibliotecas, enquanto a competência em informação vai além, englobando elementos que visam à autonomia do sujeito na sua relação com a informação, incluindo-se o desenvolvimento do pensamento crítico (CAVALCANTE; BONALUMI, 2014).

Para Campello (2003) existem dois momentos importantes que influenciaram a construção inicial do sentido da information literacy: o primeiro ocorreu nos anos 1970, nos Estados Unidos (EUA) quando o empresário Paul Zurkowski (1974), enquanto presidente da organização voltada à indústria da informação naquele país, recomendou que o governo americano investisse na formação da população em information literacy, a fim de que as pessoas pudessem utilizar a variedade de produtos 
de informação disponíveis pelo setor; o segundo momento aconteceu em 1976, quando se passou a utilizar essa terminologia para indicar uma formação de cidadãos competentes no uso da informação, em condições de tomar decisões pautadas na responsabilidade social.

Conforme Santos (2017), essa competência é abordada principalmente pela classe bibliotecária, mesmo que seu surgimento tenha acontecido fora do ambiente da biblioteca. Enfim, os bibliotecários até hoje têm procurado assumir a responsabilidade pela temática e por sua denominação. Entretanto, referências a iniciativas de Colnfo na Europa são bastante raras e fragmentadas, sendo que a maioria tem origem nas publicações advindas do Reino Unido. Parte do problema de compreender as origens das atividades europeias de competência em informação está relacionada às questões de idioma e terminologia (VIRKUS, 2003). Vários estudiosos europeus discutiram os conceitos de Colnfo e habilidades informacionais, como por exemplo, a relação entre a educação do usuário e essa competência que é apresentada por Fjällbrante Malley (1984, p.123) ao mencionarem:

[...]É umtermo 'guarda-chuva' equeincorporahabilidades de estudo, de aprendizagemede comunicação, bem como habilidades no uso da biblioteca. Claro que não há nada inteiramente novo em tudo isso - vários bibliotecários têm argumentado sobre algumas dessas linhas de ação antes. A novidade é que o pessoal envolvido neste trabalho decorre das diferentes origens de ensino, pesquisa e bibliotecas, trazendo com eles experiência e o conhecimento especialista dessas diferentes áreas (tradução nossa).

Em geral, no contexto da Ciência da Informação, o discurso da competência em Informação está centrado no acesso efetivo e na operacionalização da informação pelo indivíduo, e isso tem levado a debates sobre o que é essa competência e como deve ser descrita e praticada na sociedade contemporânea. Existem defensores que conceituam essa competência como um aprendizado baseado em habilidades, onde é equiparada às habilidades informacionais exigidas no processo de busca de informações. Por outro lado, a competência em informação é conceituada como um fenômeno complexo, que atua como um catalisador para a aprendizagem. Na maioria das vezes, isso reflete os processos de pesquisa e pensamento crítico, que são compreendidos por diferentes profissionais da informação e educadores. Da mesma forma, também existem debates na literatura especializada sobre como a competência em informação deve ser ensinada: incorporada em disciplinas ou como uma especialidade autônoma.

A competência em informação na sociedade contemporânea pode ser identificada, por meio de três requisitos:

a) Competência em informação para a cidadania: compromisso ativo com a comunidade, política e desenvolvimento global mediante o livre acesso e o uso crítico de dados e informação; 
b) Competência em informação para o crescimento econômico: fomento desenvolvimento de empresajá existentes e de nova criação mediante ouso criativo e intensivo do conhecimento e a combinação eficiente dos serviços de informação; e

c) Competência em informação para a empregabilidade: educação, formação e desenvolvimento continuam de todos os conhecimentos, habilidades e estratégias necessárias para o acesso e 0 êxito econômico (BELLUZZO; FERES, 2013, p. 68).

Ainda, analisando as origens da Colnfo, nos anos 1980 recebeu a influência da tecnologia da informação, configurando-se uma ênfase instrumental e restrita (SANTOS, 2011) e, nos anos 1990 considera-se época que foi marcada pela busca de fundamentação teórica e metodológica para 0 desenvolvimento de programas dessa competência, em todo o mundo e em várias organizações, ampliando-se os horizontes de sua importância e aplicação. Destaca-se a publicação do livro Information Power (1998) que auxiliou a assimilação do conceito de competência em informação pela classe bibliotecária (CAMPELLO, 2003).

Por outro lado, de acordo com premissas de Castells (2000) a sociedade está inserida em uma revolução tecnológica, na geração de conhecimentos e no processamento da informação com alterações substanciais na forma como nos comunicamos. Além disso, vivencia-se um mundo global e digital e uma economia informacional, no qual as tecnologias mudaram a forma e as relações humanas.

No tempo presente a informação precisa ser tratada sob dois aspectos: primeiro como um direito humano que leva em consideração o capital informacional para a vida. Em segundo lugar, ela deve ser entendida como um bem, político, econômico, social e cultural, pois se insere de forma indiscutível em todas as dinâmicas sociais da atualidade. Percebendo a informação como um bem, é natural que essa se torne um elemento em disputa na sociedade, num mundo onde a competição entre os indivíduos é estimulada, ela pode significar alguma espécie de vantagem sobre o outro, desde as discussões políticas, até o mundo do trabalho e a convivência social.

Destaca-se que, na atualidade, deve existir o propósito de lidar com as questões de sobrecarga de informação decorrente da geração de informações a um ritmo cada vez mais rápido e em transações e compartilhamentos de natureza digital. Muitas são as discussões sobre em que bases se fundamentam a emergência da lógica dessa nova realidade social na formação educacional, no ambiente de trabalho nas organizações, mas, principalmente, na relação das pessoas com a informação, destacando-se que a natureza desse campo de estudo envolve o conjunto de ideias em relação ao conhecimento aplicado para interpretar e compreender situações ou fenômenos.

Pode-se dizer que os paradigmas comunicacionais e educacionais emergentes, alinhados à pesquisa virtual apoiada na Internet com seus milhões de sites de busca, ao mesmo tempo em que 
permitem encontrar informações sobre todas as áreas do conhecimento em grande quantidade, criam novos problemas e uma grande complexidade para saber buscar, selecionar e utilizar essas informações na construção de conhecimento com aplicabilidade à inovação e ao desenvolvimento social. Emerge, assim, nesse cenário a necessidade da Competência em Informação (Colnfo).

Após esse briefing sobre a competência em informação, salienta-se que o propósito deste artigo é contribuir com a descrição teórica dessa competência, oferecendo um panorama desde suas origens até as tendências que a integram na sociedade contemporânea, enquanto um movimento de cidadania e aprendizado ao longo da vida de importância vital para que todos tenham acesso e façam uso inteligente da informação para construir o conhecimento de forma assertiva, ética e legal e aplicá-lo às questões de garantia da sustentabilidade, desenvolvimento social e inovação no cenário de mudanças em curso.

\section{DESENVOLVIMENTO}

\subsection{Competência em informação de um cenário ao protagonismo no âmbito internacional}

Para o entendimento da Colnfo é preciso esclarecer o que seria "competência", antes de mais nada. Ressalta-se, a priori que nos últimos anos, o tema competência entrou para a pauta das discussões acadêmicas e empresariais, associado a diferentes instâncias de compreensão: em nível da pessoa (a competência do indivíduo), das organizações (as core competences) e dos países (sistemas educacionais e formação de competências) (FLEURY; FLEURY, 2000, 2001). Na perspectiva adotada neste artigo, a competência vai além de um estoque de conhecimentos teóricos e empíricos detido pelo indivíduo e tampouco acha-se centrada na tarefa. Reportamo-nos a Zarifian (2003) que mencionou ser a competência a inteligência prática para situações apoiadas em conhecimentos adquiridos e os transformam significativamente quanto maior a complexidade das situações que envolvem o contexto social.

Ainda, é possível adotar como norteador a contribuição de Santos e Belluzzo (2015) que enfatizam os aspectos que envolvem a competência (força propulsora que nos move na execução de ações com utilização de recursos adequados que direcionam as tomadas de decisões); capacidade (conhecimento formal e informal que é adquirido pelos indivíduos durante suas experiências ao longo da vida e continuamente em constante transformação); habilidade (maneira de executar e a forma 
analítica e crítica de visualizar e efetuar ações presentes que resultarão em êxito futuro); e atitude: (o comportamento, realização da ação para obtenção dos propósitos, alcance dos objetivos e metas iniciais idealizadas e colocadas em pratica pelos indivíduos). Esses aspectos acham-se apoiados em Patricia S. Breivik, que em 1985, então diretora responsável pela Biblioteca da UNIVERSITY of Colorado, em Denver, nos Estados Unidos, expandiu o conceito da Colnfo ao interpretá-lo como um conjunto integrado de habilidades, conhecimentos e atitudes. Assim, também para Dudziak (2001) o conceito deixou de ser relacionado somente às habilidades técnicas e ao contexto da biblioteca, passando a corresponder à compreensão e avaliação de informações associados à pesquisa como a relevância, eficiência e a eficácia, além do pensamento crítico e criativo, traduzindo isso nesse mesmo trinômio.

Apoiando-se no novo contexto social e em suas transformações no movimento à Revolução 4.0 em curso é que a Competência em Informação (Colnfo) pode ser compreendida envolta em duas dimensões que ajudam no desenvolvimento humano e social: a primeira "[...] voltada ao domínio de saberes e de habilidades de natureza variada levando a interpor práticas em sua realidade e a outra dimensão ligada a um olhar crítico com ações e compromissos voltados às demandas e necessidades da sociedade atual" (BELLUZZO, 2007, p. 34).

Além disso, cabe destacar que ainda existem questões de ordem terminológica em relação à Colnfo, contando-se com diferentes traduções internacionais advindas do termo original em inglês, Information Literacy. Entretanto, o termo Competência em Informação, vem sendo utilizado por ser considerado o que melhor representa sua compreensão do ponto de vista semântico. E porque, no Brasil, esse termo consolidou-se em 2011, no seminário "Competência em Informação: cenários e tendências", realizado durante o XXIV Congresso Brasileiro de Biblioteconomia, Documentação e Ciência da Informação, na cidade de Maceió (AL), com a "Declaração de Maceió sobre a competência em informação" (DECLARAÇÃO..., 2011) considerado marco histórico para essa área no nosso contexto. A exemplo de outros países, em outro marco histórico, na "Carta de Marília" (UNESP, 2014) foi recomendada a utilização da sigla - Colnfo - para indicar essa competência, a fim de que pudesse haver diferenciação daquela tradicionalmente utilizada para a ciência da informação $(\mathrm{Cl})$. A decisão pela tradução do termo information literacy para "competência em informação" foi recomendada também pela Unesco, por meio da publicação OVERVIEW of information literacy resources worldwide, em suas duas edições $(2013,2014)$, organizadas por Horton Jr., "o que consolidou a utilização dessa expressão como tradução oficial para o português do Brasil, além de inseri-la na logomarca da Unesco para a Colnfo" (FURTADO; BELLUZZO, VITORIANO, 2019, p. 77). 
Seguindo as contribuições de importância ao longo da história da Colnfo, em 1987, Carol Kuhlthau descreveu em publicação intitulada Information Skills for an Information Society: a REVIEW of research, sobre a estreita relação entre essa competência e a educação. Ainda, também ofereceu outras contribuições de importância para o desenvolvimento da Colnfo nas bibliotecas escolares (KUHLTHAU,1989, 1993). Essa autora destacou a integração da Colnfo ao currículo, além da apropriação e do uso das tecnologias de informação mais acertadas ao seu aprendizado, conforme mencionou Dudziak em sua dissertação de mestrado:

O ponto importante é a integração da IL ao currículo, o que significa entendê-la não como uma disciplina isolada, autônoma e desprovida de contexto, mas sim em harmonia com o universo do aprendiz. Ao referir-se à proficiência investigativa como meta educacional e ao amplo acesso aos recursos informacionais, Kuhlthau amplia o conceito de IL, desfazendo a noção corrente na época de que as habilidades informacionais se restringiam à biblioteca e aos materiais científicos bibliográficos. O foco estava no aprendizado. A autora também se situa frente à realidade das tecnologias de informação, fornecendo-nos sua real dimensão: as tecnologias de informação são apenas ferramentas de aprendizado (KUHLTHAU apudDUDZIAK, 2001, p.29).

Em 1989, a American Library Association(ALA) publicou o documento de sua autoria denominado Report of the Presidential Committee on information literacy: Final Reportque estabeleceu a função social da Colnfo e sua relação com os cidadãos, destacando também sua importância para as questões envolvendo a solução de problemas e a tomada de decisão como exercícios de cidadania apoiados na importância da informação (DUDZIAK, 2001). Esse relatório enfatizou a necessidade de implantação de um novo modelo de aprendizado voltado para o desenvolvimento de pessoas com pensamento crítico e voltadas à aprendizagem ao longo da vida, a fim de se minimizar lacunas entre currículos, salas de aula e bibliotecas. O foco central seria a formação de profissionais e cidadãos integrados de forma eficiente e eficaz na sociedade (DUDZIAK, 2003).

Destaca-se, ainda, que os anos de 1990, foram marcados pela consolidação da competência em informação em diversos programas desenvolvidos com parcerias entre a área de educação e as bibliotecas. Assim, a Assembleia Geral das Nações Unidas elegeu o ano de 1990 como o International Literacy Year, o que trouxe consigo a existência de uma década de ações voltadas à redução do analfabetismo (BEHRENS, 1992). De acordo com Hatschbach (2002) nesse período a Colnfo procurou atender aos objetivos comuns, de forma cooperativa e educadora, aos bibliotecários e professores. Vale lembrar que existe uma distinção na conceituação da Colnfo nessas parcerias e que surge de diferenças epistemológicas e metodológicas, as quais influenciam como essa competência é pesquisada e, portanto, compreendida, como por exemplo, quando se utilizam as abordagens de pesquisa comportamentalista VERSUS construtivista. Essas variações de perspectiva levaram a contrapontos 
entre os bibliotecários que tendem a adotar uma abordagem centrada na biblioteca para a Colnfo e se concentram no desenvolvimento de habilidades de pesquisa eficazes, e os professores/ pesquisadores que a entendem como parte do processo de aprendizagem.

Em 1997, foi criado o "[...] Institute for information literacy da ALA - ACRL, cujo objetivo era capacitar bibliotecários e dar suporte à implementação de programas educacionais no ensino superior" (DUDZIAK, 2003, p. 27). Outra contribuição de importância é de autoria de Christine Bruce (1996), pesquisadora australiana, que em sua tese intitulada Information literacy: a phenomenograph, utilizando-se da fenomenografia, criou um modelo relacional, que analisava a Colnfo como um fenômeno experimentado por indivíduos que interagem e vivenciam o universo informacional, ou seja, que usam a informação de forma competente (CAMPELLO, 2009). Ainda em Bruce (1997) vamos encontrar a afirmação de que as pessoas tendem a aprender via uma estrutura de ensino e de acordo com circunstâncias que podem variar conforme suas necessidades. Dessa maneira, a ênfase não precisa ser nas habilidades, conhecimentos ou atitudes próprias, mas sim na situação e no contexto onde a Colnfo se desenvolve. Essa mesma autora contribuiu com as chamadas SEVEN faces of Information Literacy, concepções para a Colnfo, descrevendo que essa competência é um fenômeno que sobressai à questão do desenvolvimento de competências, uma vez que pondera as experiências vividas pelas pessoas, sendo que a denomina como uma abordagem situacional. Essas facetas compreendem o que segue, em síntese:

- Concepção 1 - Baseada nas tecnologias da informação, sendo que a Colnfo acha-se centrada na utilização dessas tecnologias para a a recuperação e a comunicação da informação, tendo importância central a possibilidade de acesso à informação individual e em rede. Considera a necessidade de disponibilidade e de infra-estrutura para que as pessoas sejam consideradas competentes em informação.

- Concepção 2-Baseada nas fontes de informação, considerando que a Colnfo de pende do conhecimento dessas fontes e da habilidade de acessar à informação por meio delas de forma independente ou pela ação de um mediador. Detaca, ainda, que as fontes podem compreender uma grande variedade de formatos, incluindos os eletrônicos e até mesmo as pessoas. Diferentes orientações para o problema da recuperação das informações deram origem a outras subcategorias: conhecer as fontes de informação e sua estrtura, usá-las com autonomia e com flexibilidade ou por intermedio de mediador.

- $\quad$ Concepção 3 - Baseada na informação enquanto um processo, no qual a Colnfo é vista como centro de atenção, com o entendimento de que os processos de informação compreendem 
as estratégias aplicadas pelos usuários ao se deparar com uma situação nova epara a qual apresentam falta de conhecimento ou de informação, sendo importante estar apoiado na sistematização de um processo para encontrar e utilizar a informação necessária.

- Concepção 4 - Baseada no controle da informação, no qual a Colnfo é considerada como a capacidade de controlar a informação e sua organização para recuperação posterior, sendo que tem a ver com o armazenamento da informação, em geral na forma de documentos e mediante um sistema que assegure uma fácil recuperação. Assim, assume que toda informação deve ser selecionada sobre a base de seu valor de uso futuro na pesquisa ou no ensino.

- Concepção 5-Baseada na construção do conhecimento, na qual a Colnfo é experimentada como um processo de construção pessoal de conhecimentoem uma nova árrea de interesse, destacando-se a utilização crítica da ifnormação, sendo que esta se converte em um objeto de reflexão e se apresenta para cada usuário com formas únicas e individualizadas, expandindo a intenção de armazenamento da informaçãoa e implicando na adoção de perspectivas pessoais.

- Concepção 6 - Baseada na extensão do conhecimento, na qual a Colnfo é experimentada como um conhecimento ampliado, incorporando a criatividade e/ou intuição, com a criação de sentido e sendo a obtenção de novos pontos de vista uma característica desta concepção. A utilização da informação continua sendo o centro de atenção; porém, não se restringe à construção do conhecimento como na conepção anterior e compreende uma extensão do mesmo, sendo que a intuição e a criatividade passam a ser fatores que contribuem para a utilização eficaz da informação.

- Concepção 7 - Baseada na inteligência, sendo que a Colnfo é identificada como o uso inteligente da informação produzida a partir do que se aprendeu, em benefício de outros; ou seja, incorporando a noção de ética, de valores pessoais e sociais no uso da informação. Aqui, considera-se que o diferencial desta concepção é o uso da informação com sabedoria, o que ocorre em um grande e diferenciado número de contextos, incluindo a emissão de juízos, a tomda de decisões e a pesquisa. Implica em colocar a informação em um contexto mais amplo e vê-laà luz de uma maior experiência (história, temporal e sociocultural), podendo ser utilizada de diferentes formas qualitativamente. A consciência dos valores e da ética pessoal são necessárias para poder utilizar a informação desta forma (BRUCE, 2003).

Um outro marco internacional de importância foi a publicação da American Library Association $(A L A, 1998)$ do relatório denominado como A Progress Report on Information Literacy: An Update on the 
American Library Association Presidential Committee on Information Literacy: Final Report que atualizou questões identificadas em relatório anterior $(A L A, 1989)$ acerca do cenário de ações e investimentos nos Estados Unidos para a área da Colnfo. Esse novo documento mencionou principalmente as tecnologias, ressaltando, entretanto, que o foco nas mesmas não seria suficiente para utilizar todo o potencial próprio da sociedade da informação, tanto na área de educação, quanto nos negócios. Para tanto, foi mencionado que um futuro mais promissor só surgiria se todos os jovens desenvolvessem as habilidades concretas de competência em informação. O relatório mencionou seis recomendações apontadas na versão anterior, trazendo seus avanços e indicando novas sugestões visando outras evoluções, ponderando-as como ações prioritárias para o novo milênio no contexto americano, segundo Furtado (2019). Apoiando-nos em síntese de Santos (2020), algumas dessas ações podem ser destacadas: 1 - Recomenda-se também que a Information Literacy seja promovida como uma prioridade para todas as áreas da educação, incluindo 0 treinamento da força de trabalho;2 - O National Forum on Information Literacy deve chegar a organizações adicionais que representam o governo, as empresas e a educação; 3 -Devem continuar a encorajar, apoiar e rastrear pesquisas e projetos sobre Information Literacy; 4 - Precisam explorar e implementar formas de divulgar melhor a informação sobre os modelos existentes para os principais grupos políticos; e, 5 - Devem desenvolver um plano para trabalhar com programas de formação de professores e o Conselho Nacional de Avaliação da Formação de Professores para infundir os requisitos de competência em informação em programas de graduação e pós-graduação na educação de professores.

Ainda em 1998, de acordo com Campello (2003), surgiu, nos Estados Unidos, uma nova versão do documento Information Power (publicado inicialmente nos anos de 1980), tendo sido elaborado pela American Association of School Librarians (ACRL), uma divisão da American Library Association (ALA). Esse documento trouxe consigo a concepção de que o bibliotecário deveter aliderança na implementação do conceito de Colnfo no ambiente escolar. Assim, apresentou um conjunto de recomendações que favorecem o desenvolvimento de habilidades em informação da fase de educação infantil até o ensino médio, porém, não apenas em termos teóricos, mas reforçando os termos práticos de sua aplicação, tendo sido incluídas nove habilidades, as quais foram reunidas em três grupos: competência para lidar com a informação, informação para aprendizagem independente e informação para responsabilidade social. O Information Power pode ser considerado um documento que proporcionou a assimilação da Colnfo pela classe bibliotecária (CAMPELLO, 2003).

Correia, Teixeira (2003) fornecem um panorama de alguns dos desenvolvimentos em conceitos e práticas associadas à competência em informação em todo o mundo, revelando o paradoxo de que, 
embora a Colnfo, na concepção desses autores, seja uma disciplina fundamental da sociedade da informação e da economia do conhecimento e bem compreendido em seu sentido mais amplo, fez pouco progresso educacional, exceto por algumas exceções em países como Austrália, EUA, Canadá e Reino Unido.

Saliente-se que as discussões dos últimos anos sobre a Colnfo e a natureza dos conceitos intensificaram-se novamente no Reino Unido, surgindo diferentes abordagens ao usar os termos 'competência em informação' e 'habilidades de informação' e muitas definições foram sugeridas por diversas organizações, instituições e autores. Decorrente dessas abordagens, outro fator de influência para o desenvolvimento da Colnfo, em 1999, foi a criação e divulgação do modelo denominado SEVEN Pillars of Information Literacy for Information Skills in Higher Education: SCONUL (Reino Unido) e que ordenou os principais elementos da Colnfo em sete vertentes principais: "reconhecer uma necessidade de informação; determinar maneiras de abordar a lacuna de informações; construir estratégias de pesquisa; localizar e acessar informações; comparando e avaliando; organizando, aplicando e comunicando-o e, finalmente, sintetizando e criando novos produtos com base nele. (ARP; WOODWARD; GIBSON, 2007, p.24, tradução nossa). 0 modelo dos 'Sete Pilares de Competência em Informação' atendeu à solicitação do relatório de ICT Literacy do Conselho Nacional de Pesquisa daquele país para um maior enfoque na educação em Tecnologia da Informação (TI) em conjunto com os esforços do National Forum on Information Literacy dos Estados Unidos. Em decorrência, foi acrescentado o foco em habilidades de tecnologia da informação, em combinação com habilidades em Colnfo e com as recomendações do National Forum on Information Literacy e os Partnership for 21st Century Skills referentes à Information and Communication Technology Skills (TIC),com base em Educational Testing ServICE desenvolvido pela ICT Literacy Assessment para a educação superior - ICT literacy foi similarmente "organizado em categorias de eventos (definir, acessar, gerenciar, integrar, avaliar, criar e comunicar)" (ARP; WOODWARD; GIBSON, 2007,p.24).

Vale lembrar que em vários países da Europa, o desenvolvimento da Colnfo ocorreu derivado da educação do usuário e da instrução sobre o uso da biblioteca no contexto escolar. Na Espanha, um país europeu que se destaca, os termos relacionados, conceitos e aplicações em programas para o desenvolvimento da competência de informação estão presentes na pesquisa e na prática, principalmente, durante os anos 1990 em diante, mas o termo espanhol alfabetización informacional (ALFIN) e o conceito adotado como sendo o da ALA (1989), só começam a aparecer na literatura internacional especializada por volta de 2000 (GÓMEZ HERNÁNDEZ; PASADAS UREÑA, 2003). 
Ressalta-se que muitos esforços demonstram que, desde os anos de 1990 até a atualidade, inúmeros trabalhos vêm sendo desenvolvidos com o objetivo e empenho de buscar uma fundamentação teórica que contribua à consolidação da Colnfo, surgindo muitas análises e reflexões acerca de sua conceituação, além da elaboração de padrões e indicadores, parâmetros e diretrizes norteadoras à sua aplicação nos diferentes contextos sociais.

Assim, nos anos 2000 em diante, vale destacar que a Association of College \& Research Libraries - ACRL (2000), apresentou o documento Information Literacy Competency Standards for Higher Education, contemplando padrões e indicadores de Colnfo que até o momento constituem norteadores para o planejamento e aplicação de programas que visam ao desenvolvimento dessa competência. Ainda, a ACRL (2000) contribuiu com um conceito importante para a Colnfo, ao descrevê-la como um conjunto de habilidades exigido dos indivíduos para reconhecer quando a informação é necessária, mencionando que essas habilidades devem permitir que os indivíduos possam localizar, avaliar e usar efetivamente a informação, constituindo a base para a aprendizagem ao longo da vida, esta última um dos pilares de apoio dessa competência. Além disso, no documento Global PERSPECTIVES on Information Literacy ou 'Perspectivas Globais sobre a Competência em Informação', elaborado pela ACRL (2017), é possível observar uma amplitude e abrangência do conceito sobre Colnfo, destacando a importância do contexto para construção do aprendizado que é constituído por partes integrantes que são indissociáveis da atividade e das situações em que são produzidas.

A 'Proclamação de Alexandria' éum marco histórico para a Colnfo e se reconhece com o título "Os Faróis da Sociedade de Informação" - The Alexandria Proclamation "Beacons of the Information Society'(FARÓIS, 2005). Esse documento validou a importância da inclusão social, do desenvolvimento socioeconômico e da promoção do bem-estar das pessoas mediante a existência de políticas, programas e projetos de Colnfo e aprendizado ao longo da vida, requisitos considerados fundamentais para o trabalho e qualidade de vida. Em decorrência, temos que:

[...] é preciso preparar ações e traçar estratégias regionais e mundiais de difusão e institucionalização do tema que, no entendimento traçado durante o Colóquio, tem referência com a organização de encontros regionais e temáticos, desenvolvimento de programas educacionais direcionados a bibliotecários e demais profissionais da informação, inclusão da competência em informação nos currículos da educação básica e também na educação continuada (DUDZIAK, 2008, p.43).

Salienta-se que existeavisão de Rader(2002) sobreaCoInfo, quandomencionou que asociedade do futuro precisará ser povoada por cidadãos bem informados que formarão "a pedra fundamental para uma sociedade que seja justa e possua potencial de crescimento econômico" (RADER, 2002, p. 
2). Conta-se, ainda, com uma nova visão acerca da conceituação da Colnfo oferecida e aceita pelos pesquisadores desse tema em caráter internacional. Trata-se da contribuição de Addison e Meyers (2013, p.1) que afirmaram que essa competência deve ser analisada sob os seguintes aspectos:

1) competência em informação como a aquisição de habilidades da "era da informação", 2) competência em informação como cultivo de hábitos mentais, e 3) competência em informação como engajamento em informação e conhecimento das pessoas comalto nível de instrução (tradução nossa).

Addison e Meyers (2013) ao agruparem as definições de Colnfo em três categorias: um conjunto de habilidades, pensamento crítico ou como um fenômeno social ou prática, forneceram uma estrutura para seguir a progressão das definições de Colnfo no decorrer do tempo, considerando-se que as primeiras definições eram predominantemente baseadas em habilidades, mas logo seguidas pela introdução de modelos cognitivos, que influenciaram fortemente a mudança das definições baseadas em habilidades para a maneira de pensar no desenvolvimento dessa competência em diferentes ambientes, especialmente o acadêmico.

Mais recentemente, este foco foi ampliado para examinar a transição da escola e da educação continuada para a universidade, mas também no local de trabalho, reconhecendo a afirmação da UNESCO de que a Colnfo é um processo para aprendizagem ao longo da vida (UNESCO, 2016). Assim, houve a necessidade de sua identificação como um atributo da empregabilidade na sociedade em que se vive.

Cheuk (2008) considera a importância atribuída aos negócios no valor e nos desafios da sobrecarga de informações. Ela é uma das pesquisadoras que atua nessa área e recomenda a adoção mais ampla de conceitos de Colnfo e abordagens da educação em ambiente de trabalho. Embora, em geral seja considerado uma inter-relação importante entre a Colnfo e a empregabilidade (CRAWFORD; IRVING, 2012), até recentemente havia poucas pesquisas sobre este tema na literatura especializada. Este é um campo que necessita de pesquisas e estudos com maior aprofundamento, considerando-se que envolvem e apoiam o desenvolvimento humano e o organizacional, exigindo uma transversalidade nos diferentes sistemas de gestão nas organizações contemporâneas. Reforça isso a UNESCO quando identificou este gap e recomendou a identificação das aplicações da Colnfo em diferentes surVEYS (CATTS, 2010).

Mais recentemente, diante da chegada da era digital, vivemos em um contexto repleto de máquinas inteligentes conectadas que agilizam a comunicação de modo instantâneo, sendo um ecossistema social e cultural mediado pela tecnologia digital, o que requer conhecimentos, habilidades, 
atitudes e valores que permitam a expressão e convivência com a mesma de forma adequada e assertiva. Além disso, também é uma forma de observar os avanços das técnicas atuais de transformação da sociedade em comparação a outras anteriores. Essa era parece emergir em substituição à era industrial que, por sua vez, substituiu a era da agricultura. Assim, ao menos em tese, passamos por um terceiro ciclo de renovações de ideias, ações e pensamentos que marcaram a história da humanidade. Além disso, tendo em vista as transformações sociais em curso, atualmente, tem importância 0 estabelecimento de uma estreita relação entre essa competência e a competência midiática ( media literacy), considerando-se que a informação e a comunicação são consideradas situações borderlines na sociedade contemporânea. Considera-se como sendo esta última Como consequência, a UNESCO recomendou que essas competências devem ser articuladas e desenvolvidas em conjunto, conforme Wilson et al. (2013, p. 11) destacaram:

[...]Movida pelos avanços tecnológicos nas telecomunicações, manifesta-se também a proliferação das mídias e de outros provedores de informação, por meio de grandes quantidades de informação e conhecimento que são acessadas e compartilhadas pelos cidadãos. Com esse fenômeno, e partindo dele, existe o desafio de avaliarmos a relevância e a confiabilidade da informação sem quaisquer obstáculos ao pleno usufruto dos cidadãos em relação aos seus direitos à liberdade de expressão e ao direito à informação. É nesse contexto que a necessidade da alfabetização midiática e informacional (AMI) deve ser vista [...].

O movimento de inter-relação entre a competência em informação e midiática tem sido impulsionado por um conjunto de tecnologias disruptivas como robótica, inteligência artificial, realidade aumentada, big data, nanotecnologia, impressão 3D, biologia sintética e loT (Internet das Coisas), onde cada vez mais, dispositivos, equipamentos e objetos, são conectados uns aos outros por meio da internet. Muitas destas tecnologias estão ainda em fase inicial e seu real potencial não foi explorado em sua totalidade, mas, de fato criam-se novas demandas sociais e ocupacionais e, em decorrência, cada vez mais tanto a Colnfo como a competência midiática têm sido consideradas condição sine qua non para que a cidadania e o aprendizado ao longo da vida possam ser exercidos com a sua totalidade de oportunidades e benefícios à sociedade.

Encontramos em Chandra (2015) a reafirmação da importância da Competência em informação ao mencionar que ela é amplamente aceita na atualidade, sendo que por esta razão está ganhando a condição de fator essencial na Ciência da Informação, na Educação e em outros setores do cotidiano como a Comunicação e a Administração. Para esse autor, seu propósito é permitir lidar com as questões de sobrecarga de informação decorrente da geração de informações a um ritmo cada vez mais rápido, procurando auxiliar a transformar a informação em conhecimento, o que capacitará as 
pessoas a adquirir e usar informações apropriadas para cada situação de forma inteligente em todo 0 mundo. Isso alinhado às necessidades de desenvolvimento da competência midiática.

Em suma, pode-se dizer que existem também vários outros exemplos de iniciativas e colaboração em nível global envolvendo a Colnfo e a competência midiática, as bibliotecas e os profissionais da informação nos países desenvolvidos, principalmente da Europa e Estados Unidos, contextos onde essas competências estão cada vez mais sendo reconhecidas e consolidadas.

\subsection{Competência em informação: um overview no Brasil}

Registre-se que o tema 'Competência em informação' têm sido bastante pesquisado e divulgado nos países desenvolvidos e os estudos e pesquisas sobre a Colnfo, em âmbito internacional, acham-se direcionados às questões, tais como: construção de modelos teóricos; desenvolvimento de padrões e diretrizes que sejam parâmetros para os modelos; aplicação dos padrões à realidade social e ao ambiente digital emergente, envolvendo reflexões sobre os fatores críticos resultantes de experiências comprovadas e em andamento para que apresentem êxito de acordo com métodos de avaliação adotados. No contexto brasileiro, entretanto, essas iniciativas têm ocorrido ainda em pequena escala, constituindo-se em estado inicial de difusão e investigação, emergindo na literatura nacional com relatos de estudos teóricos e de algumas experiências de sua aplicação, ressentindo-se de políticas públicas para esse novo cenário social.

À medida que procuramos desenvolver habilidades de Colnfo nas pessoas, precisamos lembrar que a busca de informações é um processo dinâmico - as necessidades de informação podem surgir ou se dissipar rapidamente, e a "necessidade" é mutável. Não devemos assumir modelos simples e lineares de busca de informação (CASE, 2012; COLE, 2012). Sabe-se também que um condutor importante da tomada de decisão é a conformidade social, de modo que, se alguém está fazendo algo, outros são mais inclinados a fazer o mesmo. Isto é importante quando se considera que técnicas irão incentivar a mudança de comportamento - a Colnfo é um elemento de importância e uma base necessária, mas insuficiente, para a mudança nesta era digital. Portanto, se considerarmos as condições e o contexto social, a complexidade do comportamento da informação ou as práticas de informação em geral, as confusões cognitivas comuns e a exclusão digital, essa diversidade de complicações e limitações reduz significativamente o potencial reivindicado pela Colnfo, inclusive, para melhorar as relações sociais além dos desafios de ordem política. Ainda, na concepção de Vitorino e Piantola 
(2011) existem quatro dimensões para a Colnfo que constituem partes de um todo de competências que não se mantêm sozinhas ou sobrevivem sem as outras dimensões. As dimensões são chamadas de técnica (habilidades e conhecimentos em determinada área e que possibilitem as pessoas encontrar, avaliar e usar a informação de que se necessitam), estética (capacidade de percepção das pessoas, por meio de suas relações com outras pessoas, com o ambiente e, ainda, com a forma de lidar com a informação), ética (comportamento ético e o uso responsável da informação para o bem comum)e política (participação das pessoas nas decisões de cunho coletivo da sociedade).

Igualmente, é preciso entender como as habilidades, conhecimentos, atitudes, valores e a expressão de Colnfo são desenvolvidos porque não dependem apenas da experiência. Isso vale especialmente para as habilidades de avaliação. Da mesma forma, habilidades eficazes e eficientes para encontrar informações exigem tempo e esforço para aprender. Convém salientar que a informação é organizada de maneira complexa, e, isso pode dificultar o seu acesso, avaliação e uso de forma inteligente. Além disso, muitas pessoas não têm a devida compreensão acerca do contexto da informação - como ou por que ela é produzida, nem os propósitos para os quais diferentes tipos de informação são disponibilizados (JULIEN, 2016). Além disso, em países em desenvolvimento, como é o caso brasileiro, caracterizado por ser continental e apresentar inúmeros paralelos e contrastes em suas diferentes regiões, ainda convivemos com problemas de ordem econômica e nem todos têm acesso às tecnologias digitais de informação e comunicação. Convém lembrar que esses cidadãos, de modo geral, em todos os níveis de idade estão praticamente obrigados a uma comunicação de forma digital e interativa , sendo que o presencial deixou de ser a forma de comunicação tradicional cedendo espaço para a interatividade e a virtualidade. Ainda, a disseminação e intensiva utilização das tecnologias de informação e comunicação (TIC) trouxeram novos desafios aos usuários, delineando novas rotinas e relacionamentos nos consumidores e produtores de informação, o que traz consigo a necessidade da CoInfo em articulação com a competência midiática como fator imprescindível ao desenvolvimento humano, social e à inovação no país.

Ressalta-se, entretanto, que no Brasil, a competência em informação apresenta estudos pioneiros com as contribuições de Caregnato (2000); Belluzzo (2001); Dudziak (2001); Campello (2002) e Hatsbach (2002). A partir de então, várias pesquisas e projetos foram desenvolvidos por instituições, pesquisadores e profissionais da informação envolvendo esse tema. Isso tem propiciado a consolidação necessária para a essa competência como uma área de importância no cenário social contemporâneo. Por outro lado, no tocante à Colnfo em ambientes de trabalho, Bassetto (2018) também apresenta de 
maneira sintetizada alguns autores nacionais que trouxeram diferentes contribuições acerca da Colnfo nesse contexto organizacional brasileiro, salientando dentre eles Coelho et al. (2013) que podem ser considerados pioneiros na implementação de um programa de desenvolvimento da Colnfo em integração com o Departamento de Recursos Humanos, em ambiente organizacional da Transpetro, subsidiária da Petrobras e que abrangeu um total de aproximadamente nove mil funcionários. Para esse autor, as contribuições, em síntese, envolveram principalmente: conceituações e princípios teóricos; valorização e uso efetivo da informação na formação de professores e outros profissionais na sociedade do conhecimento; aprendizagem ao longo da vida; gestão da informação e do conhecimento; inovação e desenvolvimento social; redes de conhecimento; busca e compartilhamento da informação; atributos da pessoa competente em informação; tomadas de decisão e solução de problemas; integração de ambientes educacionais e profissionais; ética e legalidade; interdisciplinaridade com outras áreas; inclusão social; requisitos de perfil e desenvolvimento profissionais.

Uma contribuição de interesse sobre a Colnfo é a de Hatsbach e Olinto (2008) e que apresenta um rápido cenário da evolução desse tema no âmbito internacional e também no Brasil, apresentando uma visão da evolução da Competência em Informação como campo de estudos dentro da Ciência da Informação, destacando trabalhos que se tornaram marcos na área, assim como tendências temáticas que têm surgido ao longo do tempo, incluindo o tratamento do tema na América Latina. Além disso, Dudziak (2010) também ofereceu um cenário de importância sobre a Colnfo, apresentando uma análise crítica a respeito das pesquisas e da produtividade científica desse tema no contexto brasileiro. Destacase aqui, para aqueles interessados em maiores informações sobre a Colnfo no contexto brasileiro, uma revisão da literatura nacional que permitiu o estabelecimento do estado da arte desse tema no período compreendido entre 2000 e 2016, a qual se apresenta em forma de E-Book intitulado como "A Competência em Informação no Brasil: cenários e espectros", e que foi publicado pela Associação Brasileira de Educação em Ciência da Informação (ABECIN), de autoria de Belluzzo (2018). Essa publicação traz à tona os principais momentos de destaque do tema 'Competência em Informação', abordando desde sua evolução de conceito, extraída da literatura da área de Ciência da Informação, evidenciando os principais pesquisadores deste campo científico, analisando a produção científica de 2000 a 2016 e, portanto, abrangendo dezesseis anos de pesquisa. Ainda, apresenta também as barreiras e os avanços dos estudos e pesquisas que envolvem a temática em foco no cenário nacional, tratando também de outro aspecto que se refere à apropriação e incorporação do conceito no âmbito das políticas públicas, bem como no que tange às práticas desenvolvidas no cenário nacional. Assim, 
registra-se esta contribuição como uma recomendação de leitura porque não existe a intenção de ser redundante nesse sentido.

No entanto, considera-se ser importante lembrar, em síntese, que é possível identificar que a Colnfo tem ganhado representatividade por meio da divulgação de manifestos e declarações como um pré-requisito educativo para o desenvolvimento, inovação e inclusão social mediante o uso crítico, reflexivo e responsável da informação, destacando-se a "Declaração de Maceió sobre a competência em informação" (FEBAB, 2011), "Manifesto de Florianópolis sobre a Competência em Informação e as Populações Vulneráveis e Minorias (MANIFESTO..., 2013) e a "Carta de Marília" (UNESP, 2014), documentos resultantes dos primeiros seminários realizados no contexto brasileiro e que deram maior visibilidade nacional e internacional ao tema, destacando-se a Federação Brasileira de Associações de Bibliotecários, Cientistas da Informação e Instituições (FEBAB), órgão representativo das associações e organismos que envolvem a área da Ciência da Informação no Brasil e filiada à IFLA, que foi pioneira e vem promovendo várias ações para fomentar e consolidar a Colnfo no país, em parcerias com universidades e o apoio do Instituto Brasileiro de Informação Científica e Tecnológica (IBICT-MCTIC).

Quanto à pesquisa, os resultados indicaram a existência de atividades em instituições, individuais ou integradas e que se acham representadas em grupos de pesquisa devidamente cadastrados no Conselho Nacional de Pesquisa (CNPq). Os grupos de pesquisa (GP) cadastrados são agrupados e divulgados pelo "Diretório dos Grupos de Pesquisa no Brasil" que oferecem uma base corrente de informações atualizadas pelos líderes de grupos, pesquisadores, estudantes e dirigentes de pesquisa das instituições participantes. Nesse sentido, foi possível identificar que a maioria dos grupos se acha constituída nas universidades públicas e, também, advinda da área de Ciência da Informação. Os resultados revelam, ainda, uma diversificação acerca dos enfoques e das abordagens que decorrem dos estudos e pesquisas desses grupos sobre a Colnfo, sendo que maioria adota o termo "Competência em Informação" para as denominações dos mesmos ou para intitular suas linhas de pesquisa em torno das concepções e dimensões sobre o que dedicam seus olhares. Ainda, com certeza, muitos artigos e teses e dissertações publicadas acham-se envolvidos com contribuições originadas no âmbito dos membros integrantes desses grupos, daí a sua grande importância para a implementação e a consolidação da Colnfo no cenário nacional. (BELLUZZO, 2018).

Nota-se crescimento no número de eventos e de posicionamentos importantes a respeito da temática, fruto das discussões e experiências práticas realizadas por profissionais da Biblioteconomia e Ciência da Informação brasileiras, além de outras áreas como a Educação e a Administração. Nesse 
sentido, segundo Simeão et al. (2019) no nosso contexto, a Associação Nacional de Pesquisa e PósGraduação (ANCIB) promove o Seminário de Competência em Informação, desde o ano de 2014, como parte da programação do Pós-ENANCIB, em parceria com o Instituto Brasileiro de Informação em Ciência e Tecnologia (IBICT-MCTIC), UNESP e UnB com o objetivo de criar um espaço de reflexão, discussão e compartilhamento de experiências e práticas sobre a Colnfo e sua articulação com as Redes de Conhecimento Colaborativo, desenvolvidas por pesquisadores da Ciência da Informação no Brasil, reconhecendo ser necessária uma integração entre pesquisadores e instituições, para promover a garantia da consolidação dessa competência.

Mais recentemente, ainda de acordo com Simeão et al. (2019, p. 448), "[...] foi elaborado, em ação conjunta com a Rede Cariniana e o Projeto Brasília 2060, uma "Proposta de diretrizes para desenvolvimento de políticas em repositórios de documentos científicos [...]" a fim de nortear a elaboração de políticas abrangendo o Repositório de Colnfo visando a sua criação no âmbito do IBICT (MCTIC). Essas autoras, na sequência, mencionam que "Em seguida, optou-se por criar a Biblioteca Virtual da Colnfo (IBICTMCTIC) utilizando para abrigar sua coleção, também a plataforma Data Verse [...]" com o propósito de oferecer maior visibilidade e disponibilidade para a sistematização e armazenamento de pesquisas e da produção científica na área. (SIMEÃO et al., 2019, p. 448).

Outro evento de importância nessa mesma direção, ocorreu em Florianópolis, em 2019, denominado como 'I Seminário Internacional de Competência em Informação (I SEICIn) e o III Seminário de Pesquisas e Práticas sobre Competência em Informação de Santa Catarina (III SEPCIn)'. Foi organizado pelo Núcleo de Estudos e Pesquisas sobre Competência em Informação (GPCIn) da Universidade Federal de Santa Catarina (UFSC) e trouxe consigo reflexões profundas sobre a Colnfo no contexto contemporâneo, contando com a participação de pesquisadores e profissionais da área de Ciência da Informação, além de convidados na condição de especialistas brasileiros e estrangeiros.

No ano de 2020, a FEBAB, que desde 2003 vem promovendo e fomentando a Colnfo por meio do apoio e organização de eventos tais como: oficinas, workshops, cursos, palestras, seminários etc., criou o 'Grupo de Trabalho de Competência em Informação' buscando constituir ações e estratégias para fortalecer a criação de uma rede colaborativa e associativa que objetiva trilhar a conscientização, a promoção e o desenvolvimento da competência em informação no cenário nacional (FEBAB, 2020).

Ressalta-se a expressão de Isa Maria Freire (UFPB) ao mencionar os eventos e as contribuições já realizados sobre o que denomina de "Movimentos da Competência em Informação" (2015, n.p.): 
A emergência e a importância da Colnfo para o Brasil nos últimos anos, indica fortemente a necessidade de compartilhamento de experiências e vivências aplicáveis à realidade brasileira, para o enfrentamento de desafios que exigem e implicam na redução das iniquidades sociais e desigualdades regionais, no que diz respeito às políticas de acesso e uso da informação para o exercício da cidadania e o aprendizado ao longo da vida.

Diante da síntese histórica apresentada, é possível afirmar que é necessária, ainda, a abertura para novos espaços de reflexão e discussão desse teor a fim de que haja a consolidação efetiva desse tema e, em decorrência, sua aplicabilidade a diferentes contextos no Brasil.

\section{CONSIDERAÇÕES FINAIS}

É importante ressaltar que a implementação de programas para o desenvolvimento da competência em informação em articulação com a competência midiática depende de fatores de natureza vária, tais como: políticas públicas de caráter internacional e nacional, abordagens de ensinoe aprendizagem, acordos e parcerias público-privadas, integração entre docentes e bibliotecários, sendo recomendável uma ação estratégica que envolva abordagem colaborativa apoiada em metodologias ativas e baseadas em solução de problemas.

Destaca-se, ainda, que novos aprendizados também são reconhecidos como essenciais para o desempenho social, uma vez que a coleta de informações, manipulação e aplicação são atividadeschave em qualquer tipo de organização. Aqueles que não tiverem boas habilidades de informação e uso de tecnologias digitais serão marginalizados na vida privada e pública. Portanto, fazendo um recorte no cenário que apresentamos, pode-se dizer que essas habilidades se acham presentes na competência em informação amalgamada com a competência midiática, o que inclui a capacidade de encontrar e utilizar a informação, porém, implica em ir mais além dessas dimensões, pois, compreende aspectos, tais como: a comunicação, a colaboração e o trabalho em rede, uma vez que envolve também questões como a consciência social na era digital que se vivencia, o conhecimento da segurança e governança da informação e a criação de nova informação para gerar novo conhecimento. Assim, o domínio dessas competências e das habilidades que as compõem, certamente, implicam na fluidez com a Tecnologia da informação e da Comunicação (TIC), com os métodos de pesquisa, a lógica, na reflexão crítica, o discernimento e a racionalidade, isto porque a informação continuará sendo uma massa de dados indiferenciados até que todas as pessoas tenham igualdade de oportunidades para tratá-la com discernimento e espírito crítico, analisá-la, selecionar seus diferentes elementos e incorporar aqueles que acreditem sejam mais significativos para a construção de conhecimento. 
Tem importância também salientar que a Colnfo, construída em torno de uma diversidade de práticas, modelos e habilidades, permite a possibilidade de vislumbrar vários cenários para enquadrar e pensar o futuro com suas tendências e perspectivas. De uma abordagem transversal a um desenvolvimento disciplinar autônomo, alguns cenários têm evidência e podem ser descritos, conforme apontados por Saunders (2009) e que foram adaptados e sintetizados, sendo apresentados a seguir:

- Cenário 1 - Envolve dimensões de natureza semiótica: considerando a existência de novas linguagens, de diferentes sistemas de signos que estão evoluindo e se encontram cada vez mais em integração com multimodais contínuos (hashtag, link, twiter, podcast, content curator, youtube, instagram, streaming etc.)

- Cenário 2 - Compreende a dimensão de natureza tecnológica - considerando-se os avanços dos dispositivos conectados e dos softwares em evolução constante, o que implica em maiores possibilidades de uso, de interação, de criação, de comunicação e de relações.

- Cenário 3 - Diz respeito à dimensão de acesso, uso, consumo e divulgação de informação e de conteúdos - com a ampliação de serviços e possibilidades em multiplataformas, cada vez mais acessíveis a uma audiência universal, a qual até mesmo personaliza suas experiências mediante a chamada "computação em nuvem".

- Cenário 4-Relaciona-se com a dimensão da ação informativa e comunicativa: os múltiplos formatos das fontes de informação e comunicação que se consolidaram na última década, impõem enfrentar os desafios em termos de interação e da comunicação digital. Assim, as redes sociais, alnternete o uso de dispositivos conectados, em especial os celulares com sua mobilidade, trouxe consigo uma nova lógica para lidar com a informação e a comunicação para a qual as pessoas precisam estar capacitadas, sendo a competência em informação articulada à competência midiática um imperativo deste século XXI.

- Cenário 5 - Articula-se com a dimensão ética e legal-considerando-se que a democratização na produção de informação e de conteúdos favorece uma liberdade expressão e de criação sem precedentes. Isso traz consigo boas e más práticas no acesso se uso da informação e dos recursos digitais porque, muitas vezes, cada usuário age de forma isolada com o seu dispositivo e nem sempre utiliza os padrões de ética e legalidade, além de acreditar na maioria das informações e conteúdos que recebe diariamente e de efetuar o seu compartilhamento. 
Deve-se considerar que os programas de ensino e aprendizagem voltados para o acesso e uso inteligente, legal e ético da informação, mediados pelos recursos digitais que se encontram disponibilizados, irão permitir construir conhecimento aplicável à realidade social para o enfrentamento das transformações em curso. Trata-se, portanto, de um marco para a atuação necessária em políticas sociais de aprendizado contínuo em relação à informação, ao conhecimento e ao uso dos meios de comunicação contemporâneos, buscando diminuir as lacunas existentes, para que os desafios impostos pela economia informacional e o digital não se convertam cada vez mais em fatores de exclusão social, principalmente, porque se deve pretender que os cidadãos possam exercer a cidadania de forma efetiva e assertiva, transparecendo um comportamento e exercício democráticos mediante participação ativa como atores históricos e sociais no cenário presente, contribuindo com um legado de sustentabilidade, desenvolvimento social e inovação para as gerações futuras.

\section{REFERÊNCIAS}

ACRL 2000. Information Literacy Competency Standards for Higher Education. Disponível em: http://www.ala.org/acrl/sites/ala.org.acrl/files/content/standards/standards.pdf. Acesso em: 20 set. 2020.

ACRL 2017. Global perspectives on information literacy fostering a dialogue for international understanding.Disponível em: http://www.ala.org/acrl/sites/ala.org.acrl/files/content/publications/ whitepapers/GlobalPerspectives_InfoLit.pdf Acesso em:20 out. 2020.

ADDISON, C., MEYERS, E. Perspectives on information literacy: a framework for conceptual understanding. Information Research, v.18, n.3, (2013). Disponível em: http://www.informationr.net/ ir/18-3/colis/paperC27.html. Acesso em: 14 out. 2020.

AMERICAN LIBRARY ASSOCIATION. Report of the presidential committee on information literacy: final report. Chicago: ALA, 1989. Disponível em: www.ala.org/acrl/publications/whitepapers/ presidential. Acesso em: 26 set.2020.

AMERICAN LIBRARY ASSOCIATION. A progress report on information literacy: an update on the American Library Association Presidential Committee on Information Literacy final report. Chicago: ALA, 1998.

AMERICAN LIBRARY ASSOCIATION. Presidential Committee on Information Literacy: final report (2008). Disponível em: http://www.ala.org/acrl/publications/whitepapers/presidential. Acesso em:23 set. 2020.

ARP, L.; WOODWARD, B. ; GIBSON,C. Information literacy and IT fluency:convergences and divergences. Reference \& User Services Quarterly,v.46, n.59, p.23-26, 2007.Disponível em: https:// 
www.semanticscholar.org/paper/Information-Literacy-and-IT-Fluency\%3A-Convergences-ArpWoodard/fd5c2e71a1d6397aacc4d1847a05a3a8030c3e88 Acesso em: 15 out. 2020.

\section{BASSETTO, C. L. A competência em informação como elemento inovador no apoio às microe} pequenas empresas: uma modelagem teórico-prática aplicável aos programas de capacitação do SEBRAE/SP. 2018. 260 f. Tese (Doutorado em Ciência da Informação) - Faculdade de Filosofia e Ciências, Universidade Estadual Paulista(UNESP)-Campus de Marília, Marília, 2018.

BEHRENS, S. J. Undergraduate library and information skills in a distance learning environment. 1992. 429 f. Tese (Doutorado em Ciência da Informação) - University of South Africa (UNISA), Pretoria, 1992. Disponível em: http://uir.unisa.ac.za/bitstream/handle/10500/18073/thesis_behrens sj.pdf?sequence=1\&isAllowed=y Acesso em: 27 set. 2020.

BELLUZZO, R.C.B. Competência em informação no Brasil: cenários e espectros. São Paulo, ABECIN, 2018. Disponível em: https://labirintodosaber.com.br/wp-content/uploads/2019/08/EbookCompet\%C3\%AAncia-em-informa\%C3\%A7\%C3\%A30-no-Brasil-cen\%C3\%A1 rios-e-espectrosProfa.-Regina-Belluzzo-2018.pdf Acesso em: 27 set. 2020.

BELLUZZO, R. C. B.; FERES, G. G. Competência em informação, redes de conhecimento e as metas educativas para 2021: reflexões e inter-relações. In: BELLUZZO, R. C. B; FERES, G. G.; VALENTIM, M. L. P.(Orgs.). Redes de conhecimento e competência em informação: interfaces da gestão, mediação e uso da informação/organização. Rio de Janeiro: Interciência, 2015. 414p.; p.1-35.

BELLUZZO, R. C. B. A information literacy como competência necessária à fluência científica e tecnológica na sociedade da informação: uma questão de educação. In: SIMPÓSIO DE ENGENHARIA DA PRODUÇÃO DA UNESP, 7., 2001, São Paulo. Anais Eletrônico... São Paulo: Unesp, 2001. Disponível em: http://www.simpep.feb.unesp.br/ana8.html. Acesso em: 13 out. 2020.

BELLUZZO, R. C. B. Construção de mapas: desenvolvendo competências em informação e comunicação. Bauru: Cá entre Nós, 2007.

BELLUZZO, R. C. B.; FERES, G. G. Competência em informação: de reflexões às lições aprendidas. São Paulo: FEBAB, 2013. Disponível em: http://labirintodosaber.com.br/wp-content/uploads/2017/12/ compete $\%$ CC $\% 82$ ncia-em-informac\%CC $\% A 7 a \% C C \% 830$-de-reflex0\%CC\%83es-a\%CC\%80slic\%CC\%A70\%CC\%83es-aprendidas1.pdf. Acesso em: 27 set. 2020.

BREIVIK, P.S. Putting libraries back inthe information society. American Libraries, v. 16, n. 1,p. 703723, Nov. 1985.

BRUCE, C.S. Las siete caras de la alfabetización en información en la enseñanza superior. Anales de documentación, n. 6, p. 289-294, 2003. Traducción de Cristóbal Pasadas Ureòa (Biblioteca,Facultad de Psicologla, Universidad de Granada). Disponível em: https://core.ac.uk/download/pdf/234778219. pdf Acesso em: 25 set. 2020.

BRUCE, C.S. Information literacy: a phenomenography.PhD Thesis, 1996, University of New England, Armidale. Disponível em: https://rune.une.edu.au/web/handle/1959.11/6730 Acesso em: 20 set. 2020. 
CAMPELLO, B. S. Biblioteca escolar : temas para uma prática pedagógica. Belo Horizonte: Autêntica, 2002.

CAMPELLO, B. dos S. Letramento informacional no Brasil: práticas educativas de bibliotecários em escolas de ensino básico. 2009.208f. Tese(Doutorado em Ciência da Informação) -Universidade Federal de Minas Gerais (UFMG), Belo Horizonte, 2009.

CAMPELLO, B. dos S. O movimento da competência informacional: uma perspectiva para o letramento informacional. Ciência da Informação, Brasília, v.32, n.3, p.28-37, set./dez. 2003.

CAREGNATO, S. E. O desenvolvimento de habilidade informacionais: o papel das bibliotecas universitárias no contexto da informação digital em rede. Revista de Biblioteconomia \& Comunicação, Porto Alegre, v.8, p.47-55, 2000.

CASE, D.O. Looking for information: a survey of research on information seeking, needs and behavior, 3.ed. Bingley: Emerald Group Publishing Ltd., 2012.

CASTELLS, M. La era de la información: economía, sociedad y cultura. In: CASTELLS, M. La sociedad en red. Madrid: Alianza Editorial, S. A., 2000. v. 1.

CATTS, R. 2010. UNESCO. Information literacy indicators: validation report. Disponível em: https:// unesdoc.unesco.org/ark:/48223/pf0000158723. Acesso em: 20 set. 2020.

CAVALCANTE, L. de F.B.; BONALUMI, M. C. Educação de usuários e o desenvolvimento da competência informacional em escolas públicas. Inf. Prof., Londrina, v. 3, n. 1/2, p. 93 -114, jan./ dez. 2014.

CHANDRA, S. Information literacy: a review of literature. Internation Research Journal of Multidisciplinary studies. V.1, n.5 (2015). Disponível em: http://irjms.in/sites/irjms/index.php/files/ article/view/60/44. Acesso em: 17 out. 2020.

CHEUK, B. 2008. Delivering business value through information literacy in the workplace. Libri, 58, 137-143.

COLE, C. Information need: a theory connecting information search to knowledge information. Medford, NJ: Information Today, 2012.

CORREIA, A.M., TEIXEIRA, J. C. Information literacy: an integrated concept for a safer Internet. Online Information Review, v.27, n. 5, p.311-320, 2003.

CRAWFORD, J.; IRVING, C. Information literacy in employability training: the experience of inverclyde libraries. Journal of Librarianship and Information Science, v. 4, n.2, p.79-89,June 2012.

DECLARAÇÃO de Maceió. Sobre a competência em Informação. In: SEMINÁRIO SOBRE COMPETÉNCIA EM INFORMAÇÃO: CENÁRIOS E TENDÊNCIAS, 2011. Disponível em: <http://www. cfb.org.br/UserFiles/File/Declaracao\%20de\%20Maceio\%20sobre\%20Competencia\%20em\%20 Informacao.pdf>. Acesso em: 27 set. 2020. 
DUDZIAK, E. A. Competência informacional: análise evolucionária das tendências da pesquisa e produtividade científica em âmbito mundial. Informação \& Informação, v. 15, n. 2, p. 1-22, jul./dez. 2010.

DUDZIAK, E. A. Os faróis da sociedade de informação: uma análise crítica sobre a situação da competência em informação no Brasil. Informação \& Sociedade: Estudos, João Pessoa, v.18, n.2, p.41-53, maio/ago. 2008. Disponível em: http://www.ies.ufpb.br/ojs/index.php/ies/article/ download/1704 /2109. Acesso em: 27 set.. 2020.

DUDZIAK, E. A. Information literacy: princípios, filosofia e prática. Ciência da Informação, Brasília, v. 32, n.1, p. 23-35, 2003.

DUDZIAK, E. A. A Information literacy e o papel educacional das bibliotecas. 2001. 173f. São Paulo. Dissertação (Mestrado em Ciências da Comunicação) - Escola de Comunicação e Artes, Universidade de São Paulo (USP), São Paulo, 2001.

FEBAB. Declaração de Maceió sobre a competência em informação.2011. Disponível em: http:// febab.org.br/declaracao_maceio.pdf Acesso em: 27 set. 2020.

FEBAB. Grupo de Trabalho de Competência em Informação. Disponível em:https://www.facebook. com/GT.Colnfo.febab/. Acesso em: 27 out. 2020.

FJÄLLBRANT, N.; MALLEY, I. User education in libraries. 2. ed. London: Clive Bingley, 1984.

FLEURY, A. C. C.; FLEURY, M. T.L. Estratégias empresariais e formação de competências. São Paulo: Atlas, 2000.

FLEURY, M. T. L.; FLEURY, A. Construindo o conceito de competência. Revista de Administração Contemporânea - RAC, Curitiba, v. 5, n. esp., p. 183-196, 2001. Disponível em: http://www.scielo.br/ scielo.php?script=sci_arttext\&pid=S1415-65552001000500010\&lng=en\&nrm=iso. Acesso em: 19 set. 2018.

FARÓIS da Sociedade de Informação. Versão em português do documento Beacons of the Information Society, Alexandria, 2005. Disponível em: http://www.ifl a.org/II/wsis/ BeaconlnfSocpt. html. Acesso em: 20 out. 2020.

FREIRE, I. M. Movimentos da competência em informação. 2015. Disponível em: http://dci.ccsa. ufpb.br/lti/?Movimento_Compet\%EAncias. Acesso em: 20 out. 2020.

FURTADO, R. L. A competência em informação no cenário arquivístico: uma contribuição teóricoaplicada. 2019. 364 f. Tese (Doutorado em Ciência da Informação) - Faculdade de Filosofia e Ciências, Universidade Estadual Paulista(UNESP)-Campus de Marília, Marília, 2019.

FURTADO, R. L.; BELLUZZO, R. C. B.; VITORIANO, M. C. P. Competência em informação: disciplina necessária à formação do arquivista? Acervo, Rio de janeiro, v. 32, n. 1, p. 75-91, jan./abr. 2019.

GÓMEZ HERNÁNDEZ, J. A.; PASADAS UREÑA, C. Information literacy developments and issues in Spain. Library Review, v.52, n.7, p.340-348, Oct. 2003.Disponível em: https://www.emerald.com/ insight/publication/issn/0024-2535/vol/52/iss/7 Acesso em: 15 out. 2020. 
HATSCHBACH, M. H. L. Information literacy: aspectos conceituais e iniciativas em ambiente digital para o estudante de nível superior. 2002. 108f. Dissertação (Mestrado em Ciência da Informação) Pós-Graduação em Ciência da Informação do MCT/IBICT - UFRJ/ECO, Universidade Federal do Rio de Janeiro (UFRJ), Rio de Janeiro, 2002.

HATSCBACH; M. H. L.; OLINTO, G. Competência em informação: caminhos percorridos e novas trilhas. Revista Brasileira de Biblioteconomia e Documentação: Nova Série, São Paulo, v. 4, n. 1, p. 20-34, 2008. Disponívelem: https://rbbd.febab.org.br/rbbd/issue/view/6. Acesso em:06jan. 2019.

HORTON JUNIOR, F.W.(Org.) Overview of information literacy resources. Paris: UNESCO, 2013. Disponível em: http://www.unesco.org/new/fileadmin/MULTIMEDIA/HQ/CI/CI/pdf/news/overview_ info_lit_resources.pdf. Acesso em: 10 out. 2020.

HORTON JUNIOR, F. W. (Org.) Overview of information literacy resources. Paris: UNESCO, 2014. Disponível em: https://www.ifla.org/files/assets/information-literacy/publications/unesco_composite_ document_-_final_-_2.pdf Acesso em: 10 out.2020.

JULIEN, H. Beyond the hyperbole: information literacy reconsidered. Communications in Information Literacy, v.10, n.2, p.124-131, 2016.

KUHLTHAU, C. Information search process: a summary of research and implications for school library media programs. School Library Media Quarterly, v.18, p.19-25,1989.

KUHLTHAU, C. Seeking meaning. Norwood: Ablex, 1993.

RADER, B. Information literacy : an emerging global priority. (2002). (White Paper prepared for UNESCO, the U.S. National Commission on Libraries and Information Science, and the National Forum on Information Literacy, for use at the Information Literacy Meeting of Experts, Prague, The Czech Republic.) Disponível em:http://www.nclis.gov/libinter/infolitconf\&meet/papers/rader-fullpaper. pdf Acesso em: 14 out.2020.

SANTOS, T.F.dos. Competência informacional noensino superior:um estudo de discentes de graduação em Biblioteconomia no estado de Goiás. 2011. 148 f. Dissertação (Mestrado em Ciência da Informação)-Universidade de Brasília, Brasília, 2011.

SANTOS, C.A. Competência em informação na formação básica dos estudantes da educação profissional e tecnológica. Marília, 2017. 277p. Tese (Doutorado em Ciência da Informação Universidade Estadual Paulista, Faculdade de Filosofia e Ciências, Marília, 2017.

SANTOS, C. A.; BELLUZZO, R. C. B. A competência em informação (Colnfo) como prérequisito diferencial e inovador no apoio à educação profissional. In: SIMEÃO, E. L. M. S.; BELLUZZO, R. C. B. (orgs.). Competência em Informação: teoria e práxis. Brasília: UNB, 2015. p. 89-102.

SANTOS, V.C.B. dos . Aprendizagem organizacional como instrumento de gestão de pessoas sob a ótica da competência em informação. Marília, 2020. 342f. (Tese- Doutorado em Ciência da Informação) -Universidade Estadual Paulista, Faculdade de Filosofia e Ciências, Marília, 2020.

SAUNDERS, L. The future of information literacy in academic libraries: a Delphi study. Library and The Academy, v.9, n.1, p.99-114, Jan. 2009. 
SIMEÃO, E. L. M. S. et al. Estruturação estratégica do campo científico da Competência em Informação no Brasil: integrando redes e instituições. RICl: Revista IberoAmericana de Ciência da Informação, Brasília, v. 12, n.2, p. 440-453, maio/agosto 2019. Disponível em: https://periodicos. unb.br/index.php/RICl/article/view/21769/21439. Acesso em 10 jan. 2020.

TYCKOSON, D. History and functions of reference service. In: WONG, M. A. ; SAUNDERS, L. (Eds.). Referenceand information services: an introduction 6. ed. Santa Barbara:Libraries Unlimited, 2020.p. 3-26.

UNESCO. Repensar a educação: rumo a um bem comum mundial? Brasília:UNESCO, 2016.

UNIVERSIDADE ESTADUAL PAULISTA; UNIVERSIDADE DE BRASÍLIA; INSTITUTO BRASILEIRO DE INFORMAÇÃO EM CIÊNCIA E TECNOLOGIA. Carta de Marília sobre Competência em Informação. 2014. Disponível em: Disponível em: https://www.Iti.pro.br/userfiles/downloads/CARTA_de_Marilia. pdf. Acesso em: 24 set. 2019.

VIRKUS, S. Information literacy in Europe: a literature review. Information Research, v. 8, n. 4, July 2000. Disponível em: https://www.researchgate.net/profile/Sirje_Virkus/publication/26387664_ Information_literacy_in_Europe_A_literature_review/links/54a696410cf257a6360a81ad.pdf3. Acesso em: 16 out. 2020.

VITORINO, E. V.;PIANTOLA, D. Dimensões da competência informacional. Ciência da Informação, Brasília, v. 40, n. 1, p. 99-110, 2011.

WILSON, C. et al. Alfabetização midiática e informacional: currículo para formação de professores. Brasília:UNESCO, 2013. Disponível em:file:///C:/Users/User/Downloads/220418por.pdf. Acesso em: 15 out. 2020.

ZARIFIAN, P. O modelo da competência: trajetória histórica, desafios atuais e propostas. São Paulo: Senac, 2003

ZURKOWSKI, P. Information services environment: relationships and priorities. Washington: National Commission on Libraries, 1974. Disponível em: https:/files.eric.ed.gov/fulltext/ED100391. pdf. Acesso em: 23 set. 2020. 